\title{
Special issue on continuous casting
}

\author{
Le-jun Zhou ${ }^{1} \cdot$ Ying Ren ${ }^{2} \cdot$ Pei-yuan $\mathrm{Ni}^{3}$
}

Accepted: 26 November 2021 / Published online: 21 January 2022

(C) China Iron and Steel Research Institute Group 2021

Continuous casting is considered to be one of the most important innovations in steel industry since it is first propagated by Henry Bessemer in 1846. It has many benefits, including (I) increased yield, (II) improved product quality, (III) energy saving, (IV) less pollution, (V) reduced costs, (VI) better working conditions, etc. Nowadays, more than $98 \%$ of crude steel output in the world is produced through the continuous casting process.

This process involves multiphase flow, heat and mass transfer, interfacial reaction, solidification, and so on. It is one of the most critical steps during high-quality steel production. The social development puts forward improved requirements on physical and mechanical properties of steel. This in turn requires a strict control in steel casting process with respect to steel composition, cleanliness, homogenization, solidification structure, and various defects of steel semi-product. In addition, it is necessary to further improve the production efficiency and to lower the production cost, which is important for the sustainable competitiveness of steel. To achieve above aims, technological progress in continuous casting is of great significance.

Therefore, a special issue for the Journal of Iron and Steel Research International focused on continuous casting has been organized, including seventeen papers from

Le-jun Zhou

1.j.zhou@hotmail.com

Ying Ren

yingren@ustb.edu.cn

Pei-yuan Ni

nipeiyuan@smm.neu.edu.cn

1 School of Metallurgical and Environment, Central South University, Changsha 410083, Hunan, China

2 School of Metallurgical and Ecological Engineering, University of Science and Technology Beijing, Beijing 100083, China

3 Key Laboratory of Ecological Metallurgy of Multi-metal Intergrown Ores of Education Ministry, School of Metallurgy, Northeastern University, Shenyang 110819, Liaoning, China universities and industries. We want to express our gratitude to all the editors, reviewers, and authors who contributed to the special issue. Hopefully, this special issue could be helpful to researchers and readers who are interested in continuous casting.

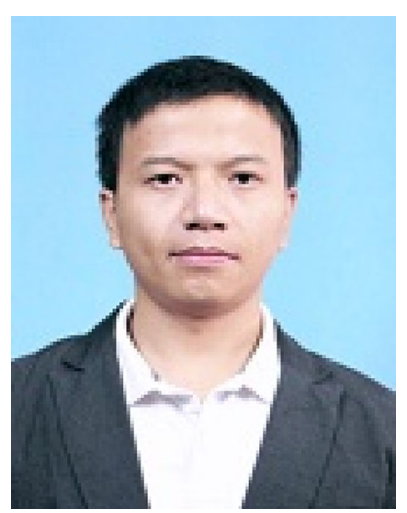

Le-jun Zhou the guest editor of this special issue, is currently an associate professor at the School of Metallurgical and Environment, Central South University, China. He obtained his Bachelor degree of Metallurgical Engineering in 2007, Master degree of Non-ferrous Metallurgy in 2010, and Ph.D. degree of Ferrous Metallurgy in 2013 from Central South University in China. He has overseas visiting research experience at University of Illinois at UrbanaChampaign in USA. His research is focused on surface quality and mold flux in continuous casting process. He has published 42 first/corresponding author journal papers collected by SCI database and 8 Chinese patents. He received 3 prizes of provincial-level science and technology awards and 5 international academic awards.

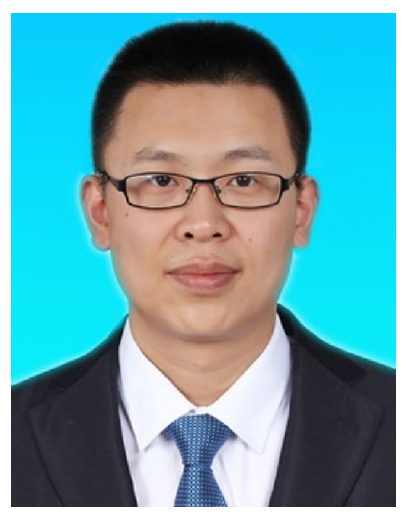

Ying Ren the guest editor of this special issue, is currently a professor at the School of Metallurgy and Ecological Engineering, University of Science and Technology Beijing, China. He obtained his Bachelor degree of Metallurgical Engineering in 2011 and Ph.D. degree of Ferrous Metallurgy in 2017 from University of Science and Technology Beijing in China. He has overseas visiting research experiences at Carnegie Mellon University in USA and Tohoku University in Japan. His research has focused on clean steel and non-metallic inclusions. He has published 1 book, 60 academic papers collected by SCI database, and 13 Chinese journal papers. He received 4 first prizes of provincial-level science and technology awards. 


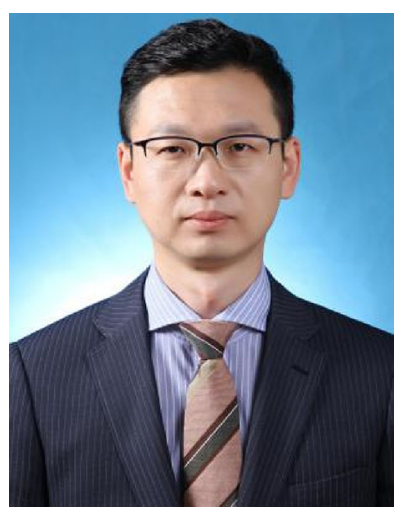

Pei-yuan $\mathrm{Ni}$ the guest editor of this special issue, is currently a professor at Department of Metallurgical Engineering, Northeastern University, China. He obtained his Bachelor degree of Metallurgical Engineering in 2008 and Master degree of Nonferrous Metallurgy in 2010 from Northeastern University in China. In 2015, he obtained his Ph.D. degree from KTH Royal Institute of Technology in Sweden. Thereafter, he worked at KTH Royal Institute of Technology as a postdoctor and Osaka University as a JSPS research fellow. His research has focused on steel metallurgy, multiphase flow and CFD simulation, high temperature metallurgy interface, functional oxide melt, big data, and machine learning. Dr. Pei-yuan Ni has published around 50 academic papers and has obtained 2 Chinese patents. 